\title{
A NOTE ON A CONJECTURE ABOUT A BETTER APPROXIMATION
}

\author{
MARIUS MiHAI BIROU
}

Abstract. In this note we give some examples which invalidate the Conjecture from [1].

Mathematics subject classification (2010): 41A36, 41A25, 41A40.

Keywords and phrases: conjecture; better approximation; exponential functions; generalized convex functions.

\section{REFERENCES}

[1] A. Aral, D. Cardenas-Morales and P. Garrancho, Bernstein type operators that reproduce exponential functions, J. Math. Ineq. 12, 3 (2018), 861-872.

[2] S. Morigi And M. NeAmtu, Some results for a class of generalized polynomials, Adv. Comput. Math. 12, 1 (2000), 133-149.

[3] Z. ZIEGLER, Linear approximation and generalized convexity J. Approx. Theory 1, 1 (1968), 420443. 